Original Article

\title{
Docetaxel Toxicity Optimization in Esophageal Squamous Cell Carcinoma Cell Line YM-1 : A Study of Cell Cycle and Doubling Time Effect
}

Boshra Haghi

(MSc) Metabolic Disorders Research Center, Golestan University of Medical Sciences, Gorgan, Iran

Marie Saghaeian Jazi iD

(PhD)Stem cell Research Center, Golestan University of Medical Sciences, Gorgan, Iran

Mahdi Zarei

(PhD) Department of Molecular Medicine, Faculty of Advanced Medical Technologies, Golestan University of Medical Sciences, Gorgan, Iran

Ayyob Khosravi iD

(PhD) Department of Molecular Medicine, Faculty of Advanced Medical Technologies, Golestan University of Medical Sciences, Gorgan, Iran

Mahboubeh Tajaldini

$(\mathrm{PhD})$ Ischemic Disorders Research Center, Golestan University of Medical Sciences, Gorgan, Iran

Jahanbakhsh Asadi

(PhD) Metabolic Disorders Research Center, Golestan University of Medical Sciences, Gorgan, Iran

Corresponding author: Jahanbakhsh Asadi

Tel: +989112239011

Email: dr.asadi@goums.ac.ir

Address: Metabolic Disorders Research Center, Golestan University of Medical Sciences, Gorgan, Iran

Received: 2019/10/13

Revised: 2019/11/03

Accepted: 2019/11/13

(c) (i) (9)

This work is licensed under a Creative Commons Attribution 4.0 License.

DOI: $10.29252 / \mathrm{mlj} .15 .2 .23$

\section{ABSTRACT}

Background and objectives: Docetaxel is a chemotherapeutic agent commonly used for treatment of many cancers, including esophageal squamous cell carcinoma. Docetaxel induces 62/M phase cell cycle arrest and ultimately cell death. In this study, we aimed to assess the effects of docetaxel on YMl cells considering exposure time and dose.

Methods: After calculating the doubling time of YMl cells, the anti-proliferative effect of different concentrations of docetaxel $(0.1-10 \mathrm{nM})$ after 24,40 and 72 hours was assessed by the standard colorimetric assay. In addition, the effect of docetaxel on cell cycle was evaluated by flow cytometry.

Results: The results showed that docetaxel toxicity was not significant until 24 hours at the tested concentrations ( $\mathrm{P}>0.05)$. In addition, the effect of docetaxel on the cells was time-dependent at all tested concentrations. 0verall, the duration of exposure to docetaxel had more significant role in docetaxel toxicity in YMl cells compared to concentration.

Conclusion: 0ur findings suggest that the cytotoxicity of docetaxel on YMI cells is time-dependent.

Keywords: Docetaxel, Cell cycle, Esophageal Neoplasms. 


\section{INTRODUCTION}

Esophageal cancer (EC) is the eighth most common cancer and the sixth most common cause of cancer-related mortality worldwide. Esophagus squamous and adenoma carcinoma are two common histopathological types of EC $(1,2)$. Esophageal squamous cell carcinoma (ESCC) is more prevalent in the northern regions of Iran, especially in the Golestan Province. Hot fluids, some medications and genetic factors are associated with the incidence of ESCC in this area (3).

Various strategies are available for treatment of ESCC including surgery, radiotherapy and chemotherapy (4). Cisplatin and fluorouracil are used as first-line therapy, and docetaxel is used as a chemotherapeutic for metastatic patients (5-7). Docetaxel is an antimitotic agent from the taxan family that is commonly used against many cancers, such as EC. Nowadays, docetaxel is used alone or in combination with other drugs and therapies in patients with prostate cancer (8), ovarian cancer, breast cancer (9) and ESCC $(7,10)$. Patients treated with docetaxel receive certain medication regimens at a given time and dose depending on the disease progression or cancer grade (11). Docetaxel disrupts the microtubule organization by binding to $\beta$-tubulin, thereby leading to Bcl-2 phosphorylation, cell cycle arrest and apoptosis. Various resistance mechanisms exist in cancer cells to reduce docetaxel efficiency such as overexpression of multi-drug resistance protein, mutation in apoptotic protein and class III $\beta$-tubulin overexpression. Nevertheless, the identification of docetaxel resistance markers is still challenging $(12,13)$. According to previous studies, taxans may have different mechanism of function depending on the time and dosage (14). It is important to use optimum doses of chemotherapeutic agents to achieve desirable outcomes without noticeable side effects (15). In this study, we aimed to assess anti-tumor effect of docetaxel on YM1 EC cell line based on exposure time and dose.

\section{MATERIAL AND METHODS}

This experimental study was approved by the ethics committee of the Golestan University of Medical Sciences (ethics code: IR.GOUMS.REC.1396.317).

Previously established human EC cell line YM1 was kindly provided by Dr. Asadi. YM1 cells were cultured in DMEM/F12 Glutamax (low glucose) (BIO-IDEA Co., Iran) supplemented with $10 \%$ fetal bovine serum (FBS) and penicillin/streptomycin at $37{ }^{\circ} \mathrm{C}$. The cells were passaged regularly at $70 \%$ confluency. For doubling time assessment, $250 \times 10^{3}$ cells were cultured for 24,48 and 72 hours, and then viable cells were counted by trypan blue staining and electron microscopy (Nikon).

Anti-proliferative effect of docetaxel (Sigma, USA) was determined by MTT assay. In brief, $5 \times 10^{3}$ cells were seeded onto 96-well plate containing medium supplemented with $5 \%$ FBS. After overnight incubation, the cells were treated with different concentrations of docetaxel $(0.1,1$ and $10 \mathrm{nM})$ for 24,48 and 72 hours. The cells were then incubated with MTT solution (Promega, USA) for two hours and later washed with dimethyl sulfoxide. Docetaxel toxicity was measured by reading absorbance at $570 \mathrm{~nm}$ using an ELISA Reader. For the cell cycle assessment, flow cytometry with PI staining (Sigma, USA) was performed. The cells treated with different concentrations of docetaxel were harvested by trypsinization and washed twice with cold phosphate buffer saline (PBS). The cells were treated with PBS containing Triton $\mathrm{X}-100(0.1 \%)$ and RNAaseI $(10 \mu \mathrm{l} / \mathrm{ml})$ for $30 \mathrm{~min}$ at $37^{\circ} \mathrm{C}$. Next, the cells were stained with PI $(10 \mu \mathrm{g} / \mathrm{ml}$ in PBS $)$ and cell cycle profile was analyzed by flow cytometry (BD Accuri System, USA). The results were analyzed using the FlowJo VX software.

Data were analyzed by SPSS two-way ANOVA and Bonferroni test at significance of 0.05 .

\section{RESULTS}

Based on the results of trypan blue staining, the number of YM1 cells duplicated approximately after 40 hours (Figure 1).

Figure1- The growth curve and doubling time of YM1 cells at 24, 48 and 72 hour.

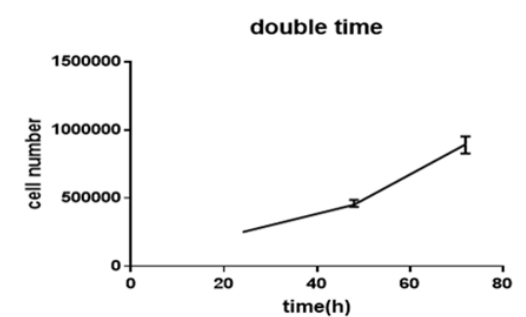


To determine effects of docetaxel, EC cells were treated with various concentrations of the drug for 24, 48 and 72 hours. The results showed that docetaxel toxicity was not significant until 24 hours at the tested concentrations. Increasing the drug concentration up to $100 \mathrm{nM}$ had a direct relationship with cell death at 48 hours vs. 72 hours (P-value $<0.01)$.

In addition, the effect of docetaxel on the cells was time-dependent at all tested concentrations (Figure 2).

The morphologic assessment of EC cells with light microscopy showed that exposure to docetaxel resulted in mitotic cell arrest with typical rounded shapes (Figure 3 ).

\section{Figure 2- Docetaxel toxicity at different concentration (10-10000 $\mathrm{nM})$ after 24, 48 and 72 hours. Docetaxel had significant toxicity in a time-dependent manner after 48 and 72 hours $(P$-value $<0.05)$. No significant toxicity was observed at the tested concentrations after 24 hours $(P$-value $=0.85)$.}

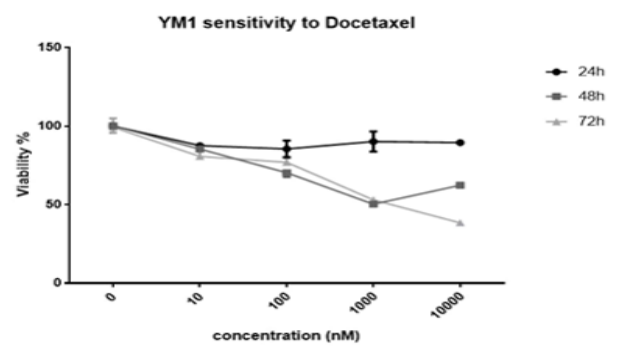

The flow cytometry assessment of cell cycle demonstrated that docetaxel induced $\mathrm{G} 2 / \mathrm{M}$ phase cell cycle arrest in the YM1 cells. We also found that the effects of the drug was not dose-dependent. Furthermore, the cell cycle arrest was followed by cell death at low concentrations during YM1 cell line's doubling time (Figure 4).

Figure 3- Morphology of YM1 EC cell line 48 hours after docetaxel treatment (10× magnification).

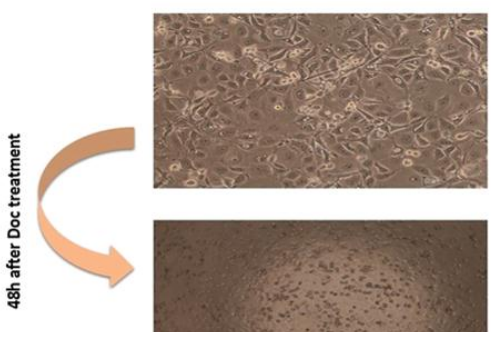

Figure 4- Effect of different concentrations of docetaxel on YM1 cells after 72 hours as shown by flow cytometry analysis.
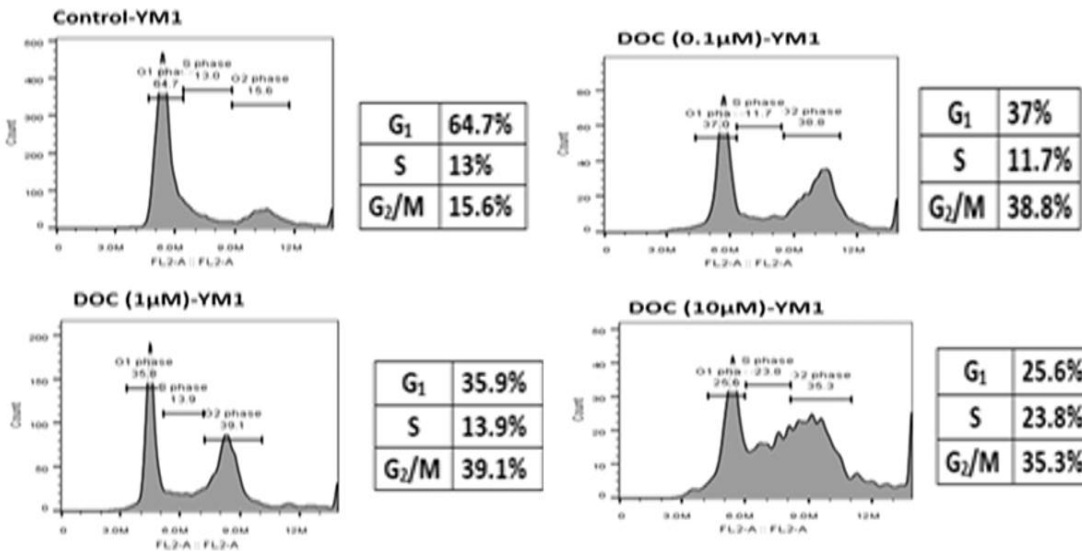

\begin{tabular}{|c|c|}
\hline$G_{1}$ & $25.6 \%$ \\
\hline$S$ & $23.8 \%$ \\
\hline$G_{2} / M$ & $35.3 \%$ \\
\hline
\end{tabular}




\section{DISCUSSION}

Docetaxel is commonly used as an effective chemotherapeutic agent in treatment of different types of cancer, such as EC. Docetaxel exerts its effects by inhibiting microtubules polymerization and $\mathrm{G} 2 / \mathrm{M}$ phase cell cycle arrest in tumor cells. Resistance mechanisms and low docetaxel efficiency have been reported by numerous studies (12). Nevertheless, the exact mechanism of docetaxel resistance in cancer cells is not understood. Therefore, maximizing the therapeutic efficacy and development of chemo-sensitization strategies at low doses will have important clinical implications. In the present study, we focused on evaluation of in vitro effects of different concentrations of docetaxel on YM1 cells line. The results demonstrated that docetaxel efficiency was strongly dependent on exposure duration. Previous studies reported that docetaxel toxicity in many sensitive mammalian cancer cells were associated with exposure time, patient status, development of nail changes and goal of chemotherapy (18). He et al. showed dose-dependent inhibitory effect of docetaxel in non-small cell lung cancer cell lines A549 and H460. With the gradual increase in docetaxel dose, the rate of cell death enhanced at 48 and 72 hours (16). We Also found a significant increase in cell death. Our results suggest that the effect of docetaxel according to the cell type and resistance mechanisms can be dependent on cell doubling References

1. Song Q, Wu J-z, Wang S, Chen W-h. Elevated preoperative platelet distribution width predicts poor prognosis in Esophageal Squamous Cell Carcinoma. Scientific Reports. 2019; 9(1): 15234. [DOI:10.1038/s41598-019-51675-y] [PubMed] [Google Scholar]

2. Cui Q, Wu C, Lin D. Genomic alterations and precise medicine of esophageal squamous cell carcinoma. Journal of Bio-X Research. 2018;1(1):7-11. [View at Publisher] [DOI:10.1097/JBR.0000000000000006]

3. Gholipour M, Islami F, Roshandel G, Khoshnia M, Badakhshan A, Moradi A, et al. Esophageal Cancer in Golestan Province, Iran: A Review of Genetic Susceptibility and Environmental Risk Factors. Middle East J Dig Dis. 2016; 8(4): 249-66. [View at Publisher] [DOI:10.15171/mejdd.2016.34] [PubMed] [Google Scholar] time. A previous study demonstrated that sensitivity of breast cancer cells to docetaxel was not associated with rapid rate of cell division. This study also showed that cells with a higher growth rate were more sensitive to docetaxel, which is in line with our findings (17).

However, Vallo et al. reported no significant correlation between cell growth kinetics and drug sensitivity in urothelial cancer cell lines RT112, RT4, 5637, T24, HT1376 and TCCSUP (19).

\section{CONCLUSION}

Our findings indicated that the effect of docetaxel on YM1 cells is time dependent. In addition, docetaxel has no significant toxicity on YM1 cells before doubling time, even at higher drug concentrations. Based on our results, the optimized toxicity of docetaxel for YM1 cells can be achieved at concentrations lower than $1000 \mathrm{nM}$ and after $72 \mathrm{~h}$ considering the cells doubling time.

\section{ACKNOWLEDGMENTS}

We would like to thank the clinical biochemistry and cell culture laboratory of Golestan University of Medical Sciences for helping us in this project.

\section{CONFLICT OF INTEREST}

The authors declare that there is no conflict of interest regarding publication of this study.

4. Tanaka Y, Yoshida K, Suetsugu T, Imai T, Matsuhashi $\mathrm{N}$, Yamaguchi K. Recent advancements in esophageal cancer treatment in Japan. Annals of gastroenterological surgery. 2018; 2(4): 253-65. [DOI:10.1002/ags3.12174] [PubMed] [Google Scholar]

5. Tamaki Y, Hieda Y, Nakajima M, Kitajima K, Yoshida R, Yoshizako T, et al. Concurrent Chemoradiotherapy with Docetaxel, Cisplatin, and 5fluorouracil Improves Survival of Patients with Advanced Esophageal Cancer Compared with Conventional Concurrent Chemoradiotherapy with Cisplatin and 5-fluorouracil. J Cancer. 2018; 9(16): 2765-72. [DOI:10.7150/jca.23456] [PubMed] [Google Scholar] 
6. Hiramoto S, Kato K, Shoji H, Okita NT, Takashima A, Honma $\mathrm{Y}$, et al. A retrospective analysis of 5fluorouracil plus cisplatin as first-line chemotherapy in patients with metastatic or recurrent esophageal squamous cell carcinoma. Journal of Clinical Oncology. 2015; 33(3_suppl): 204-. [DOI:10.1200/jco.2015.33.3_suppl.204] [PubMed] [Google Scholar]

7. Song Z, Zhang Y. Second-line docetaxel-based chemotherapy after failure of fluorouracil-based firstline treatment for advanced esophageal squamous cell carcinoma. OncoTargets and therapy. 2014; 7: 1875-81. [DOI:10.2147/OTT.S66525] [PubMed] [Google Scholar]

8. Hurwitz MD. The docetaxel debate: impact of chemotherapy in high-risk non-metastatic prostate cancer. Transl Androl Urol. 2019;8(Suppl 3):S303-S6. [DOI:10.21037/tau.2019.06.09] [PubMed] [Google Scholar]

9. Jones SE, Erban J, Overmoyer B, Budd GT, Hutchins L, Lower E, et al. Randomized Phase III Study of Docetaxel Compared With Paclitaxel in Metastatic Breast Cancer. Journal of Clinical Oncology. 2005;23(24):5542-51.

[DOI:10.1200/JCO.2005.02.027] [PubMed]

[Google Scholar]

10. Lee M-Y, Jung KS, Kim HS, Lee JY, Lim SH, Kim $\mathrm{M}$, et al. Weekly docetaxel and gemcitabine in previously treated metastatic esophageal squamous cell carcinoma. World journal of gastroenterology. 2015;21(14):4268-74. [DOI:10.3748/wjg.v21.i14.4268] [PubMed] [Google Scholar]

11. Hainsworth JD. Practical aspects of weekly docetaxel administration schedules. The oncologist. 2004;9(5):53845. [DOI:10.1634/theoncologist.9-5-538] [PubMed] [Google Scholar]

12. Bumbaca $\mathrm{B}, \mathrm{Li} \mathrm{W}$. Taxane resistance in castrationresistant prostate cancer: mechanisms and therapeutic strategies. Acta Pharm Sin B. 2018;8(4):518-29. [DOI:10.1016/j.apsb.2018.04.007] [PubMed] [Google Scholar]

13. Yan M, Wang J, Ren Y, Li L, He W, Zhang Y, et al. Over-expression of FSIP1 promotes breast cancer progression and confers resistance to docetaxel via MRP1 stabilization. Cell Death \& Disease. 2019;10(3):204. [DOI:10.1038/s41419-018-1248-8] [PubMed] [Google Scholar]
14. Hernández-Vargas H, Palacios J, Moreno-Bueno G. Telling Cells How to Die: Docetaxel Therapy in Cancer Cell Lines. Cell Cycle. 2007;6(7):780-3. [DOI:10.4161/cc.6.7.4050] [PubMed] [Google Scholar]

15. Kucukzeybek Y, Gul MK, Cengiz E, Erten C, Karaca B, Gorumlu G, et al. Enhancement of docetaxel-induced cytotoxicity and apoptosis by all-trans retinoic acid (ATRA) through downregulation of survivin (BIRC5), $M C L-1$ and LTbeta-R in hormone- and drug resistant prostate cancer cell line, DU-145. Journal of Experimental \& Clinical Cancer Research. 2008;27(1):37. [DOI:10.1186/1756-9966-27-37] [PubMed] [Google Scholar]

16. He X, Li C, Wu X, Yang G. Docetaxel inhibits the proliferation of non-small-cell lung cancer cells via upregulation of microRNA-7 expression. International journal of clinical and experimental pathology. 2015;8(8):9072-80. [PubMed] [Google Scholar]

17. Kenmotsu H, Tanigawara Y. Pharmacokinetics, dynamics and toxicity of docetaxel: Why the Japanese dose differs from the Western dose. Cancer Sci. 2015;106(5):497-504. [DOI:10.1111/cas.12647] [PubMed] [Google Scholar]

18. Risinger AL, Dybdal-Hargreaves NF, Mooberry SL. Breast Cancer Cell Lines Exhibit Differential Sensitivities to Microtubule-targeting Drugs Independent of Doubling Time. Anticancer research. 2015;35(11):5845-50. [View at Publisher] [PubMed] [Google Scholar]

19. Vallo S, Michaelis M, Rothweiler F, Bartsch G, Gust KM, Limbart DM, et al. Drug-Resistant Urothelial Cancer Cell Lines Display Diverse Sensitivity Profiles to Potential Second-Line Therapeutics. Transl Oncol. 2015;8(3):210-6.

[DOI:10.1016/j.tranon.2015.04.002] [PubMed] [Google Scholar]

How to Cite:

Haghi B, Saghaeian Jazi J, Zarei M, Khosravi A, Tajaldini M, Asadi J[Docetaxel Toxicity Optimization in Esophageal Squamous Cell Carcinoma Cell Line YM-1: A Study of Cell Cycle and Doubling Time Effect ]. mljgoums. 2021; 15(2): 18-22 DOI: 10.29252/mlj.15.2.23 